\title{
A PEDAGOGIA SOCIAL NAS IMPLICAÇÓES PRISIONAIS E PRÁTICAS ESCOLARES INTRAMUROS: REFLEXÓES DE UM estudo no Estado do Paraná
}

\author{
THE SOCIAL PEDAGOGY IN PRISON IMPLICATIONS AND \\ INTRAMURO PRACTICES: REFLECTIONS OF A STUDY IN THE \\ State of Paraná
}

\author{
Vanessa Elisabete Raue Rodrigues \\ Doutora em Educaçáo pela Universidade Estadual de Ponta Grossa. \\ Docente Colaboradora da Universidade Estadual do Centro Oeste \\ Paraná - PR - Brasil \\ ORCID: https://orcid.org/0000-0003-4943-921X \\ vanessarauerodrigues@gmail.com
}

\author{
Rita de Cássia da Silva Oliveira \\ Pós Doutorado em Educação -Universidade de Santiago de Compostela. \\ Professora Associada da Universidade Estadual de Ponta Grossa. Paraná - PR - Brasil \\ ORCID: https://orcid.org/0000-0001-9382-7573 \\ soliveira13@uol.com.br
}

Resumo: O presente trabalho teve como objetivo analisar os discursos de ressocializaçáo pela educaçấo presentes nos documentos escolares dos nove centros de educaçáo de jovens e adultos implantados nas penitenciárias estaduais do Paraná em confronto com as características estruturais destinadas à educação nestes ambientes. Desse modo, realizouse o levantamento documental disponibilizado pelas insituiçôes escolares, observando o Projeto Político-Pedagógico (PPP), o Regimento Escolar e a Proposta Pedagógica Curricular (PPC). Além disso, foram utilizados o Levantamento Nacional de Informaçôes Penitenciárias (INFOPEN) e os dados disponibilizados pela Coordenação de Educação, Qualificação e Profissionalização de Apenados (CEQP). Para a pesquisa de campo, foram investidas visitas para verificação dos espaços destinados à educaçẫo nos ambientes prisionais, observando as condiçóes estruturais como salas de aulas, biblioteca, laboratórios e demais espaços administrativos da escola. Pela perspectiva crítica, foi possível perceber que os pilares fundamentais do cumprimento de pena, pautados no processo pedagógico de reeducação da pessoa privada de liberdade, muitas vezes perdem espaço para a garantia de segurança. Esse aspecto de instabilidade e ambiguidade no referencial de açóes, demonstrou a fragilidade das mesmas e a necessidade de a escola instituir iniciativas que promovam a emancipação humana no ambiente prisional. Identificou-se, dessa forma, a fundamentação necessária para proposta de elaboração de um projeto político-pedagógico para educação nas prisóes e, pela sua dimensão, a aproximação prática da Educação Social, fundamentada no campo teórico da Pedagogia Social.

Palavras-chave: Educação. Pedagogia Social. Prisão. 
Aвstract: The present work had as objective to analyze the speeches of resocialization by the education present in the school documents of the nine centers of education of young people and adults implanted in the state penitentiaries of Paraná in comparison with the structural characteristics destined to the education in these environments. Thus, a documentary survey was made available by school institutions, observing the Political-Pedagogical Project (PPP), the School Rules and the Curricular Pedagogical Proposal (PPC). In addition, the National Survey of Penitentiary Information (INFOPEN) and the data provided by the Coordination of Education, Qualification and Professionalization of Offenders (CEQP) were used. For the field research, visits were made to verify the spaces destined to education in prisons, observing the structural conditions such as classrooms, library, laboratories and other administrative spaces of the school. From a critical perspective, it was possible to perceive that the fundamental pillars of punishment, based on the pedagogical process of reeducation of the person deprived of freedom, often lose space for the guarantee of security. This aspect of instability and ambiguity in the referential of actions has demonstrated their fragility and the need for the school to institute initiatives that promote human emancipation in the prison environment. It was identified, therefore, the necessary basis for the proposal of elaboration of a political-pedagogical project for education in prisons and, by its dimension, the practical approach of Social Education, based on the theoretical field of Social Pedagogy.

Keywords: Education. Social Pedagogy. Prison.

\section{Introduçáo}

A educação tem um apelo ressocializador e a ressocialização constitui um objetivo que pauta os discursos de reinserção social promovidos nas prisóes. Contudo, para que essa atividade aconteça ela precisa ser vista como uma responsabilidade do Estado que vise a garantia do direito social, compreendendo intervenções na estrutura do espaço físico, qualificação da demanda e da formação de profissionais e, principalmente, análise da especificidade da pessoa privada de liberdade.

Neste sentido, o presente trabalho teve como objetivo analisar os discursos de ressocialização pela educação presentes nos documentos escolares dos nove centros de educação de jovens e adultos implantados nas penitenciárias estaduais do Paraná em confronto com as características estruturais destinadas à educação nestes ambientes.

$\mathrm{Na}$ dimensão documental foram analisados os projetos políticopedagógicos, os regimentos escolares e as propostas pedagógicas curriculares, buscando identificar no discurso das escolas diante da funçáo da educação no propósito da pena e, em decorrência, na construção do 
projeto de vida da pessoa privada de liberdade. Na pesquisa de campo, a partir de uma lista de checagem que incluiu todos os espaços necessários para o funcionamento de uma instituição escolar, dentre eles os ambientes como sala de aula, biblioteca e laboratórios, foram observadas as condiçôes estruturais como iluminação, arejamento, manutenção e capacidade. A observação sistemática ocorreu em seis instituiçôes de regime semiaberto masculinas; nove instituiçôes de regime fechado masculinas e duas femininas, e uma instituição mista para tratamento psiquiátrico e ambulatorial.

Os referenciais teóricos utilizados que se destacaram foram Cordeiro (2010), a qual trata da função social do espaço penitenciário e sua precariedade nas possibilidades de ampliação da perspectiva de atendimento e Blazich (2007) ao apontar o distanciamento das gestôes prisionais e escolares, as quais adotam diferentes posicionamentos ideológicos no mesmo espaço prisional. Além disso, Silva, Moreira e Oliveira (2016) evidenciaram a perspectiva pedagógica do cumprimento de pena de prisão, com possibilidades de integração e articulação das áreas de conhecimento e profissionais que integram o corpo de atendimento prisional.

A partir da análise crítica, organizou-se o trabalho, inicialmente, abordando o texto sobre as prisóes e o perfil da pessoa presa no estado. Para isso, além de dados constantes no Levantamento Nacional de Informaçóes Penitenciárias (INFOPEN), foram analisados os dados da Coordenação de Educação, Qualificação e Profissionalização de Apenados (CEQP), vinculada à Divisão de Educação e Produção (DIPRO) do Departamento Penitenciário local.

Num segundo momento, foram levantados dados a respeito da educação nas prisôes paranaenses e problematizadas as relaçôes entre as açóes das gestóes do atendimento educacional e no cumprimento da pena de prisão. Por fim, num terceiro momento, foram abordadas as implicaçóes prisionais e as práticas escolares na prisão, relatadas pelas impressões sobre os espaços físicos durante as visitas e as constataçóes sobre a perspectiva da reinserção social postas nos documentos escolares.

Desta forma, foi possível perceber que os pilares fundamentais do cumprimento de pena, pautados no processo pedagógico de reeducação da pessoa privada de liberdade, muitas vezes, perdeu espaço em detrimento 
da segurança. Esse aspecto de instabilidade e ambiguidade no referencial de açôes, demonstrou a fragilidade das mesmas e a necessidade de a escola instituir iniciativas que promovam a emancipação humana no ambiente prisional. Para isso, defende-se a necessidade de se pensar a pena de privação de liberdade num propósito pedagógico, portanto com a necessidade de construção de um projeto político pedagógico colaborativo entre todos os profissionais da prisão.

Esse tipo de planejamento aponta para a práxis da Educação Social subsidiada no campo teórico da Pedagogia Social, indo ao encontro de uma compreensão educacional além da escolar e que pode atender às necessidades das pessoas privadas de liberdade na sua totalidade. Propóe, desse modo, uma dinâmica transformadora diante dos enfrentamentos característicos do encarceramento.

\section{As prisóes e o perfil da pessoa privada de liberdade no Estado do Paraná}

A maior parte das instituiçóes penais do estado do Paraná possui pena foi definido no final da década de 1990 e, portanto, muitas instituiçóes foram construídas posteriormente a essa data. Atualmente, o estado conta com 33 instituiçóes prisionais que mantêm a tutela de presas e presos condenados, localizadas em 14 municípios, sendo uma de responsabilidade do Governo Federal. Os municípios onde as instituiçóes estão alocadas são Piraquara (10), Foz do Iguaçu (3), Maringá (3), Londrina (3), Ponta Grossa (2), Guarapuava (2), Cascavel (2), Curitiba (1), São José dos Pinhais (1), Quatro Barras (1) Araucária (1), Lapa (1), Cruzeiro do Oeste (1), Catanduvas (1) e Francisco Beltrão (1).

Conforme o último relatório publicado do Levantamento Nacional de Informaçóes Penitenciárias de 2016, no qual constam 51.700 presos, sendo 12.408 nas cadeias públicas e 39.292 nas penitenciárias, a quantidade das instituiçóes prisionais cresceu gradativamente. Esse dado coloca o Paraná como terceiro estado que mais encarcera pessoas, ficando atrás de São Paulo (240.061) e Minas Gerais (68.354), dado que anuncia a forma 
de condenação eleita e uma questão importante ao se tentar resolver o problema de encarceramento.

Os dados apresentados no último INFOPEN, de junho de 2016, além de trazerem informaçóes importantes sobre as penas de prisão no Brasil, também representam a fonte de referências para avaliação da população paranaense privada de liberdade. O relatório indica, não obstante, que se faz necessário observar as diferenças demográficas de cada estado, comparando a população prisional com os números absolutos populacionais de cada Unidade Federativa. O Paraná tem uma taxa de aprisionamento de 459,9 presos para cada cem mil habitantes, o que corresponde a 0,47\% do total de habitantes; conta com um número de vagas de 18.365 , alcançando um déficit prisional de 33.335 vagas e uma taxa de ocupação, portanto, entre $281,5 \%$ acima dos dados nacionais. Os dados ainda revelam que o estado possui uma população presa, na sua maioria, masculina, com apenas $6,29 \%$ de mulheres, e que $87 \%$ estão destinados ao regime fechado, seja ele provisório ou de internação.

Quanto ao perfil étnico-racial, os dados paranaenses destoam ao indicar $66 \%$ de pessoas brancas presas. Esse dado pode significar uma de duas possibilidades. A primeira de que, por ser um estado majoritariamente de colonização europeia, o Paraná conta com um baixo número de pessoas negras ou pardas, observando que, segundo os dados demográficos de 2016 do Instituto Brasileiro de Geografia e Estatística (IBGE), na Pesquisa Nacional por Amostra de Domicílios Contínua (PNAD Contínua), a população branca do Paraná, nesse período, seria de 76,8\%. Nesse sentido, a população prisional refletiria essa condição. A segunda e mais provável possibilidade seria de que, embora o percentual de pessoas presas com informaçôes sobre raça/cor do estado seja de 99\%, a coleta dos dados dos presos tenha pouca rigorosidade, resultando num quadro que não reflete a realidade prisional paranaense.

Quanto à faixa etária, a população encarcerada do Paraná se mostrou jovem, totalizando $54 \%$ frente o número de pessoas presas com idade entre 18 a 29 anos, o que corresponderia, aproximadamente, a 3,4\% da população total dos jovens entre 15 a 29 anos no estado.

Essas evidências relacionam uma possibilidade crescente de reincidência, visto que as condiçôes do encarceramento, muitas vezes, pioram as possibilidades de reinserção: 
[...] a chance de reincidência criminal aumenta à medida que $o$ egresso do sistema prisional manifeste uma trajetória criminal mais extensa anteriormente ao cumprimento da pena, à medida que comece a cometer crimes cada vez mais jovens [...] (SAPORI; SANTOS; MAAS, 2017, p. 15)

Assim, estigmatizado, as possibilidades desse jovem voltar ao crime são ainda maiores. Esses marcadores sociais perpassam as tentativas de reintegraçáo da pessoa privada de liberdade, fazendo com que a reincidência só acentue as dificuldades de reinserção social, (MONTEIRO; CARDOSO, 2013).

O grau de instrução das pessoas presas nos estabelecimentos penais paranaenses representa um alerta, pois somados os alfabetizados náo regulares e aqueles com Ensino Fundamental incompleto temos 68\% de todos os sujeitos presos. Esse enquadramento aponta que a falta de acesso à educação e, consequentemente, a desqualificação do trabalhador indicam possibilidades de retorno à criminalidade, considerando as três dimensôes identificadas pelo IPEA que geram o índice de vulnerabilidade social: infraestrutura urbana, capital humano e renda e trabalho.

A educação, classificada somente como capital humano, transpassa a vida do sujeito nas três dimensôes. Isso porque infraestrutura, renda e trabalho são motivos frequentes de desistência da escola, como informa Rodrigues (2013, p. 1522):

Muitas das evasóes ocorrem por falta de vagas nas escolas, pela distância da escola à residência, mas o motivo que mais pressiona e encorpa a demanda para a desistência é necessidade de procurar o mercado de trabalho. Sendo ocasionada, ou para ajudar a família no sustento ou até mesmo para sustentá-la, quando cada vez mais cedo os jovens estão compondo família, pela gravidez e casamentos precoces.

À luz desses dados, faz-se necessário refletir sobre as dificuldades que ainda persistem de acesso à educaçáo escolar e o que representam como causa e consequência da exclusão e vulnerabilidade social. Os índices citados sinalizam um desenho de políticas públicas cujo escopo evidencia 
a sua ineficiência e, por conseguinte, ausência de direitos. Situa-se, dessa forma, como emergencial pensar a educação nos estabelecimentos penais paranaenses como uma reparação do que foi perdido fora deles.

\section{A educação prisional no Paraná}

A educação nas prisôes paranaenses acontece pela escolarização na modalidade de Educação de Jovens e Adultos (EJA), em parceria entre a Secretaria de Segurança Pública e Administração Penitenciária (SESP) e a Secretaria de Estado de Educação (SEED), firmada por Resolução Conjunta. Em 2017, segundo dados fornecidos pelo CEQP do Departamento Penitenciário do Estado do Paraná, correspondente a julho de 2017, das 19.602 pessoas com carências educacionais presas em penitenciárias naquele período, $70 \%$ frequentavam os bancos escolares. Observase que o estado não considerou os espaços de carceragem em cadeias públicas. Se consideradas todas as pessoas presas no estado, esse índice cai para 26,54\%, mas mantém um aumento de 7,54\% com relação ao relatório de 2016, utilizado como referência - contudo, ainda não é o bastante. Apesar da obrigatoriedade da oferta de educação, o estado náo conseguiu, até então, atender toda a demanda de pessoas privadas de liberdade que necessitam concluir os estudos.

Os nove CEEBJAs são: Nova Visão, Prof. Odair Pasqualini, Novos Horizontes, Wilson Antonio Neduziak, Helena Kolody, Prof. Tomires Moreira Carvalho, Prof. João da Luz da Silva Correa, Manoel Machado e Dr. Mário Faraco. Segundo investigação de campo desenvolvida no período de 2016 a 2017, dentre os vários obstáculos para alcançar o objetivo de atendimento estão a falta de estrutura física e a quantidade insuficiente de profissionais de segurança para movimentação e garantia da ordem na instituição. Estudo nas instituições escolares implantadas nas penitenciárias identificou 141 salas de aula ativas, quantidade que, para o atendimento de todos os alunos citados pela CEQP em julho de 2017, representaria, aproximadamente, 139 educandos por sala. Destes espaços, constatou-se que 60\% dos 18 espaços prisionais verificados são ambientes com pouca ventilação ou luz insuficiente. Dentre eles, $62 \%$ possuem grades que dividem educador e educando no processo de mediação do processo ensino-aprendizagem. 
Tais condições estruturais iniciam uma discussão importante quanto à intencionalidade da pena e o lugar da educação frente ao objetivo da prisão no estado. Quanto à pena de prisão, Cordeiro (2010, p. 30) afirma que

O espaço arquitetônico destinado a este fim tem importância primordial no processo de readaptação, no entanto, esquece-se de planejá-lo tendo em vista o grupo ligado à dinâmica de ato criminoso o que decorre de influências negativas da vida carcerária [...]

A falta de planejamento é refletida nos ambientes verificados na escola, pois 50\% deles ainda são adaptados, embora as Diretrizes Básicas para Arquitetura Penal, presentes na Resolução no 9/2011, previssem a obrigatoriedade de sua construção nas prisóes. As demais instituiçóes construídas anteriormente possuíam demanda educacional por um tempo bem longo, o que justificaria um 'território' garantido pela escola. Contudo, tal adaptação revelou a falta de garantia da educação como espaço de atividades permanentes. Observa-se que o fator determinante do espaço prisional é a manutençáo do enclausuramento, considerando o distanciamento entre o previsto nas determinaçóes de acordos internacionais e as condiçóes arquitetônicas.

Outra constatação foi de que, na medida em que cresce a população necessidade de espaço para o cumprimento da pena, aperfeiçocarcerária, menor é a cedência estrutural para atividades educacionais e mais enclausurada ficará a pessoa privada de liberdade. Isso também vale para as instituiçóes que sofrem com frequentes rebelióes, consequências, muitas vezes, das condiçóes da própria clausura. Assim, o efeito cíclico se instala: mais pessoas, menos tentativas de recuperação da dignidade, menos dignidade pelas condições postas, mais insatisfação, mais rebeliōes, mais tempo de prisão para as pessoas que delas participaram e cometeram novos crimes nessa crise, menos inserção de pessoas preparadas para a reinserção social, mais penitenciárias lotadas. A precária cedência do espaço prisional para educação, os efeitos causados pelo super encarceramento e outros problemas estruturais não são consequências eventuais, não ocorrem aleatoriamente: são condiçôes previsíveis pela própria origem da pena de prisão e de como ela foi tratada ao longo dos séculos:

[...] a prisão não adveio de um projeto, mas o surgimento da 
ando-se através do planejamento com ideias e regras discutidas e incorporados pelos Tratados e Convenções Internacionais, na legislação e nas resoluçôes, mas sem reflexôes conceituais que embasassem tais ideias, transformando-se de maneira cíclica, sem grandes avanços quanto à organização espacial. (CORDEIRO, 2010, p. 35)

A materialização do espaço prisional e sua organização representam o principal reflexo da falta do elemento conceitual a que ela se refere. A educação, portanto, não constitui uma prioridade na operacionalização da pena pelo fato de a própria pena carregar um único objetivo: esquecer do sujeito que cometeu crimes, enclausurando-o. Há, no entanto, uma brecha na legislação para favorecer a educação nos espaços prisionais e sobrevive, por conta própria, enfrentando o preocupante encargo de educar para a reinserção social.

Outro aspecto importante, constatado no estudo dos documentos escolares, refere-se à ausência de discussão sobre a relação entre gestão escolar e gestão prisional, não ficando claro quais são as responsabilidades de cada uma delas na elaboração de projetos de vida das pessoas presas. O fato é que mesmo a literatura da área suprime essa relação, poucas pesquisas atentam para a existência de dois tipos de gestão: a educacional e a prisional. $\mathrm{O}$ que se percebe nas pesquisas que tratam do assunto, é que as gestôes coexistem, mas não dialogam. Blazich (2007, p. 58) afirma qu

Em contexto de encierro las escuelas funcionan dentro de otras instituciones, las penitenciarias, cuya lógica de funcionamento condiciona a las primeras, no solo em los aspecto pedagógicodidácticos sino em los que refieren a la distribución del poder. Además, al responder a distintas dependencias gubernamentales su comunicación se complica ya que, em general, no funcionan articuladamente. Las dificultades de comunicación entre el personal de ambas instituciones para construir acuerdos basados en critérios comunes para el manejo de la educación, derivan em impedimentos para el normal desarrollo de las atividades académicas por razones azenas a ella. 
Nessa direção, não basta ter uma boa relação entre as duas gestóes; é preciso existir ajuda mútua e diálogo constante com vistas à elaboração de objetivos comuns. A 'boa vizinhança', muitas vezes, está assentada no silêncio, permanecendo o silêncio e a obediência da escola frente às condiçóes impostas pela gestão que mantém a tutela tanto das pessoas quanto do espaço físico.

Outro aspecto identificado por Blazich (2007) é de que a educação representa, no espaço prisional, um benefício, um prêmio para as pessoas que, para muitos responsáveis pela tutela, mereceriam castigo pelo crime que cometeram. Essa condição estabelece um clima negativo entre os profissionais da educação e da segurança. Rodrigues (2015, p. 100) aponta que

[...] o conceito do atendimento dentro da prisão está intimamente ligado com a compreensão de quais são os objetivos do preso para quando estiver fora da prisão. Num aspecto visionário, o servidor penitenciário projeta o futuro da pessoa presa a partir de seus discursos e atitudes perante as situaçóes de conflito no encarceramento. Esses fatores são demonstrados pela própria participação nas práticas e atividades propostas pela administração.

$\mathrm{Na}$ inexistência do diálogo, a escola não encontra amparo ou reconhecimento e, muitas vezes, assume o discurso da prisão como forma de 'sobrevivência', sem mesmo perceber a sua verdadeira necessidade no projeto de cumprimento de pena. Aloja-se no espaço cedido, gere seu pessoal conforme os ditames prisionais, incorpora seu discurso e alimenta, cada vez mais, a condição disciplinadora. Os documentos escolares demonstraram que a ação educativa na prisão depende da segurança e que, assim, a ideologia pregada pelos aspectos jurídicos presentes na questão prisional configura a alienação de profissionais da instituição escolar, em especial das práticas de gestão. Algumas escolas, inclusive, ao descreverem seu histórico institucional, deixam de abordar a escola para priorizar as instituições prisionais às quais estão atreladas.

Desse modo, a dialética vivida pelos profissionais da educação se mostra nas relaçóes entre os profissionais que atuam diretamente entre presos e agentes penitenciários. Essa dialética se revela na produção e reprodução do processo penal, no discurso regulador do sistema prisional e 
na fala libertadora que deveria estar presente na escola. Se houver algum resíduo de enfrentamento às condiçóes da prisão, apesar da relação apresentada na gestão, ela pode se perder no cotidiano prisional, na convivência, enfim, nas particularidades do contexto em que a escola está inserida.

Segundo Rodrigues, Quadros e Oliveira (2017), existe uma ambivalência entre as concepçóes das áreas do Direito e da Justiça e a realidade prisional, cujas contradiçóes são reveladas na disposição dos espaços físicos frente às previsôes emanadas dos documentos legais, em especial na Lei de Execuçóes Penais, a qual concebe a existência da pena e os procedimentos para que ela seja humanizada com vistas à reintegraçáo social. O ser social que, fora dos muros prisionais, foi excluído dos seus direitos sociais, continua sendo expropriado de seu direito ao conhecimento, com o agravante de que não há espaço físico escolar para participaçáo de todos no processo educativo. Além disso, não sendo a segurança partícipe direto da ação educacional, o movimento de adesão dos presos é, indiretamente, suprimido.

A escola necessita ir além, deve apoiar-se nas experiências vividas pelas pessoas presas, deve pautar-se na história de vida desses sujeitos, auxiliando na superação dos estigmas e das condiçóes preexistentes de violência. As possibilidades situam-se, portanto, na constatação e análise dos motivos que impedem reparação pela não aplicação do direito à educação nas prisôes e na superação dessas lacunas pela educação, construindo pontes nos abismos sociais.

\section{Implicaçóes prisionais e práticas escolares na prisão: reflexóes sobre a condiçáo de cárcere e possibilidades de educação pela Pedagogia Social}

O retorno aos estudos na Educação de Jovens e Adultos, momento dos mais difíceis para o educando, fica mais árduo para aquele que se encontra preso. Recuperar o tempo perdido é tentar relembrar momentos que, geralmente, se mostraram excludentes diante dos motivos que levaram à evasão escolar.

Na prisão, as lembranças da ausência de vida escolar ou de evasão revelam as decepçóes geradas pelo fracasso causado por fatores sociais, econômicos e institucionais. Os fracassos identificados podem ter eco no 
fracasso da educação e vice-versa. Mas não é somente esse estigma que permeia as atividades educacionais dentro da prisão (RODRIGUES, 2013). A pessoa privada de liberdade, ao adentrar neste local de clausura, sofre

[...] processos de admissão e testes de obediência, que podem ser desenvolvidos numa forma de iniciação e têm sido denominadas "as boas-vindas", nos quais a equipe dirigente ou os internados, ou os dois grupos, procuram dar ao novato uma noçáo clara de sua situaçáo. Recebe, por meio desse rito de passagem, "as regras da casa", um conjunto relativamente explícito e formal de prescrições e proibições que expõe as principais exigências quanto à conduta do internado. (ONOFRE, 2007, p. 13)

A prisão é conduzida por uma dinâmica que interfere diretamente nas ações e decisóes da pessoa encarcerada. Essa situação demonstra que, dentro do espaço carcerário, a preocupação da prática educativa depende da organização penitenciária na qual está inserida. Pode-se afirmar que a prática educativa está alicerçada em dois macro-pilares: o plano intramuros, de cumprimento da pena imposta no julgamento, que é apoiado por uma corrente teórico-ideológica do pensamento jurídico-penal; e o prisão, incluindo o crime, e auxilia na elaboração do 'projeto de existência' para o momento em que for beneficiado pela progressão ou indulto (perdão) da pena. (SANTOS, 2007; ONOFRE, 2007; LOURENÇO, 2011; RESENDE, 2011; SCARFÓ; BREGLIA; FREJTMAN, 2011)

No caso desse projeto, há compreensóes teórico-ideológicas distintas para elaborar os parâmetros de participação social. A compreensão aqui defendida é de que o plano extramuros precisa significar o ponto de partida para a reflexáo histórica e política à qual a pessoa, enquanto sujeito social, foi e está exposta. Defende o princípio de que, embora preso, o sujeito deve ter participação direta em sua tutela, quer seja pelo trabalho quer seja pelo estudo. Sua reinserção não pode ser construída como um momento que virá, mas como uma ação presente, que 'está sendo'. Esse fato impõe ao indivíduo preso a necessidade de refletir náo somente sobre o que o fez 'ficar fora' da escola, mas compreender como isso contribuiu para ele estar na prisão. Tal princípio parte da realidade prisional na qual a pessoa está 
envolvida, numa dinâmica em que a relação cárcere e marginalização social se encontram. Nessa realidade da divisão clara entre escola e prisão, "a educação deve promover a liberdade e o autorrespeito, e o cárcere produz degradação e repressão.” (BARATTA, 2002, p. 17)

No plano intramuros, outros dois processos seriam passíveis de observação: a desculturação e a aculturação. A primeira manifesta-se na negação das normas sociais externas à prisão, como um afastamento das responsabilidades e acontecimentos extramuros; a segunda identifica-se no rápido acolhimento das normas carcerárias pelo qual ora a pessoa presa assume a postura de um preso comportado, concordando com toda repressão carcerária, ora se apresenta como criminoso, numa organização paralela à da prisão, com regras próprias e violentas vigorando entre os reclusos (BARATTA, 2002). O plano intramuros, cujo foco é o cumprimento da pena, reflete a complexidade da convivência num espaço tão restrito e a intencionalidade da prisão como opção do Estado, condiçôes características de um espaço "de controle social, de aglutinação de interesses, de criação e recriação de aculturação delinquente, bem como de sua socialização." (SANTOS, 2007, p. 94)

O controle é marcado pelo enlace com outra característica: a impenetrabilidade. Numa instituição penal, o acesso a informaçôes ou acontece por autorização ou por quem já é prestador de serviços dentro da instituição (SANTOS, 2007). Conhecer os espaços prisionais não se faz senão por aqueles que já estiveram dentro dele, seja no papel de preso, trabalhador penal ou pesquisador. É importante ressaltar que o plano intramuros nada mais é do que uma constante busca de adesão da pessoa presa, de modo que a "prisão e as atividades que são desenvolvidas neste espaço almejam, mais do que adaptar o indivíduo à sociedade livre, adaptá-lo à vida carcerária." (SANTOS, 2007, p. 95)

A escola é parte dessa rotina que se apresenta no espaço regrado do cárcere, quer seja na organizaçáo de horários, nos regimentos e regulamentos, na normatização do comportamento, quer seja na forma como o espaço é disposto ou mesmo pelas orientaçóes do 'ser' aluno, fatos que revelam objetivos de reduzir os 'desvios' da pessoa encarcerada (RESENDE, 2011). Nessa direção, a arquitetura da prisão tem uma relação direta com o plano de cumprimento de pena. A mobilidade do educando preso para sala de aula e biblioteca, por exemplo, demonstra favorecimento ou impedimento dado à participação nas atividades pedagógicas. 
Essa caracterização mais regular ou mais singular estaria presente basicamente de duas formas: no próprio espaço arquitetônico disposto e disponibilizado para efetivar a política educacional pensada para as prisóes - seus corredores, suas salas de aula, o mobiliário à disposiçáo e as instalaçōes físicas, ou no trato interpessoal, mais ou menos flexível, que encontrávamos em funcionários, dirigentes, professores, coordenadores, entre todos aqueles responsáveis por fazer chegar essa assistência à população destinada: os presos. (LOURENÇO, 2011, p. 169)

As práticas educacionais desenvolvidas pelos professores, como o impedimento de acesso a laboratórios ou metodologias experimentais, também demonstram que a educação não é prioridade nas atividades prisionais. A falta de autonomia no acesso às atividades educacionais representa um projeto prisional que tem a disciplina como meta (LOURENÇO, 2011). Essa sujeição às normas e a limitação do espaço são características que tornam a pessoa presa dócil e útil à prisão, silenciando-a e incluindo-a num mecanismo institucional que a absorve para um processo de normalização, "uma inclusão pela exclusão.” (RESENDE, 2011, p. 50) Ao ingressar na prisão, as regras carcerárias parecem delimitar a divisão da vida da pessoa privada de liberdade, nesse caso, da pessoa sentenciada. A entrada na prisão, após a sentença, despe o sujeito de seu passado e não lhe dá perspectiva de futuro.

É como se a vida começasse com a prática do crime, com o aprisionamento, processando-se, assim, um apagamento daquilo que não esteja diretamente ligado à condição de ter sido condenado e preso pela justiça. (RESENDE, 2011, p. 51)

Diante de todo esse cenário, a escola não pode perder de vista a sua intencionalidade, na prisão ou fora dela. Para além de ser um ambiente singular, a escola tem a função social de humanizar, de promover a reflexão e de construir autonomia dos educandos na direção da emancipaçáo humana.

A escola é um espaço onde as tensôes se mostram aliviadas, o que justifica sua existência e seu papel na ressocialização do aprisionado. Inserida numa ordem que "funciona pelo avesso", 
oferece ao homem preso a possibilidade de resgatar ou aprender uma outra forma de se relacionar, diferente das relaçóes habituais do cárcere, contribuindo para desconstrução da identidade de criminoso. (ONOFRE, 2007, p. 25)

Nesse sentido, embora Baratta (2002, p. 17) afirme que "institutos penais não podem ser institutos de educação", entende-se que a escola no ambiente prisional pode, no mínimo, reduzir os danos causados pela própria prisão, permitindo a construção da identidade perdida na aculturação. A retomada do plano extramuros não tem âmbito mais fértil que o educacional.

Quanto ao plano do projeto extramuros, é importante denunciar que o trabalho educacional na prisão é uma ação criticada e vigiada pela sociedade livre. Os docentes e demais profissionais da educaçáo muitas vezes respondem quanto às suas açôes e discursos à opinião pública. A escola é etapa prévia da reinserção social, pois ela define objetivos sociais, familiares e profissionais. A educação formal na prisão precisa ser entendida como prática social e não somente como prática escolar. Embora se possa compreender que não se transforma a prisão em escola, há objetivos históricos distintos que convivem nesse mesmo ambiente e, por essa razáo, cabe significar o lugar da educação na sociedade, para encontrá-la na prisão. $\mathrm{O}$ plano extramuros reside na educação com a potencialidade de promover a construçáo de conceitos que gerem uma nova perspectiva na construção da vida fora do espaço prisional.

Definitivamente, oferecer educação em contextos de aprisionamento constitui-se como uma forma de ampliar as possibilidades de gerar um projeto genuíno de inserção social e econômica na saída da prisão e, principalmente, como 'ressignificação' do tempo transcorrido na prisão. (SCARFÓ, BREGLIA e FREJTMAN, 2011, p. 158)

Assim, a educação não deve representar somente os passos da reinserção social. Ela é um direito fundamental do ser humano, não um simples instrumento da prisão. Ela potencializa ou desperta na pessoa privada de liberdade a superação da situação prisional, dando visibilidade à possibilidade de fortalecimento na luta por direitos e dignidade humana. Além 
disso, entendendo que a educação é um eterno vir a ser, constata-se que, apesar da impraticabilidade da educação escolar na sua totalidade na estrutura apresentada pelas penitenciárias paranaenses, existem possibilidades de resistência em prol de um atendimento melhor.

É nessa direção que se pode propugnar pela necessidade do trabalho sistêmico no cumprimento da pena, representando na educação uma instituição que participa diretamente, com propósitos próprios, ligados à construção de um sujeito emancipado. A sua inclusáo no processo de aprisionamento não a destitui desse objetivo; ao contrário, pode ampliar os outros segmentos, conferindo-lhes uma concepção pedagógica. Uma instituição prisional que visa a autonomia do sujeito, propóe a integração de forças, "alinhando os conceitos de cumprimento de pena pela elaboração coletiva de um projeto pedagógico próprio da instituiçáo e tratando de repor profissionais essenciais para um atendimento sistêmico.” (RODRIGUES, 2015, p. 121)

A asserção de um projeto político-pedagógico da prisão, apresentada nas Diretrizes Nacionais para a oferta de educação para jovens e adultos em situação de privação de liberdade nos estabelecimentos penais, é analisada por Silva, Moreira e Oliveira (2016) quando apontam a integraçáo e articulaçáo das áreas de conhecimento e profissionais num propósito educativo para o cumprimento da pena de prisão, apresentando essa articulação como transformação das açôes disciplinadoras em pedagógicas. A partir dos apontamentos desses autores, compreende-se que a forma como a pena é cumprida também precisa ser revista. Para além dos muros da prisão, a participação da família e da comunidade necessita ser um dos eixos presentes nessa proposta de educação em âmbito prisional. Aponta-se, assim, que a concepção educativa, incluída nos diferentes segmentos, permitiria que a escola pudesse integrar as açóes de gestão, promovendo compartilhamentos positivos.

Considera-se, portanto, necessário fundamentar esse entendimento prático concebendo-o, não como uma gestão escolar somente, mas como uma nova forma de gestão prisional, mudando a característica da pena apresentada nos documentos jurídico-prisionais para educativa. A fundamentação dessa proposta de trabalho coletivo advém de estudos, reflexôes no contexto das experiências no cotidiano penal. Entende-se, contudo, que não há como complementar a proposta legal e ilustrada por Silva, Moreira e Oliveira (2016) propondo um desenho pedagógico a um espaço rigidamente cristalizado como disciplinador sem a fundamentação de 
uma teoria que atenda aos mesmos anseios de mudança. Essa possibilidade caracteriza-se pela práxis da Educação Social, que incorpora "a educabilidade social do sujeito e visa sua preparação para a vida em sociedade.” (SILVA, 2018, p. 11) Esse campo prático é fundamentado pela disciplina acadêmica da Pedagogia Social, que compreende a educação como parte da contribuição social coletiva, da qual a educação faz parte.

Dessa forma, o contexto apresentado e os sujeitos identificados compõem um campo de estudos e práticas que pode auxiliar na redução dos danos causados pelo encarceramento, em prol da elaboração de uma proposta de emancipação que transcenda, não somente a condição de cárcere, mas as outras mazelas a que o sujeito foi submetido antes da prisão. Silva (2018, p. 37) aponta que "a Pedagogia Social admite que a Educação se faz ao longo da vida, em todos os espaços e todos os tempos." Dessa forma, pode contribuir para que a pessoa privada de liberdade construa o seu projeto de vida no plano intramuros, enquanto a pena lhe impuser a privação, e extramuros, na análise do tempo passado frente ao futuro. A opção pela Educação Social como possibilidade de se pensar alternativas para a educação no espaço prisional se deu por algumas características, dentre elas a dimensão prática que ela contempla, que "tem como fonte as práticas pedagógicas que se transformam em teorias e iluminam ou revertem em práticas transformadoras da realidade." (CALIMAN, 2011, p. 264)

Outro aspecto importante está no fato de ela pautar-se em ações orientadas pela coletividade que compartilha as dificuldades comuns; e, por fim, por ancorar-se na perspectiva de transformação com vistas à emancipação humana. Nessa reflexão, percebe-se que a Educação Social compóe requisitos como campo de atuação, considerada a amplitude das abordagens apresentadas até entáo. Não se trata de afirmar que ela deixa de ser escolar ou de que há duas 'educaçôes' coexistindo no contexto prisional, mas que, como afirma Gadotti (2012), a pouca preocupaçáo dada à educação pelos governos vem, ao longo de décadas, limitando os propósitos educativos aos muros escolares, e no caso desta investigação, aos muros da prisão, espaço no qual a escola se instalou. Afirma-se, a partir desse apontamento, que a educação escolar também é social e que, no espaço prisional, a necessidade dessa abordagem é cada vez mais premente.

A educação no contexto prisional, tal qual na escola regular, constitui uma luta travada pela qualidade, o acesso e a permanência de todos. 
Trata-se de uma busca que é reconhecida na prática, no enfrentamento pela libertação, emancipaçáo e autonomia do sujeito (SILVA, 2011). Como apontado por Gadotti (2012), Graciani (2011, p. 287) ratifica que

neste amplo cenário econômico e cultural, reaparece a Educação, cuja má qualidade, a falta de formação de seus agentes, a pouca infraestrutura onde ocorre, dentre outros inúmeros fatores, também é responsável pela pobreza, pela desigualdade e exclusão social, não só no Brasil, mas em todas as regióes latino-americanas.

[...] ressignificar seu conceito na incorporação do "social" que denuncia as contradiçôes de um sistema em relação ao seu povo e, ao mesmo tempo, aponta para uma ação praxiológica no sentido da busca de uma didática dialética que, concretamente, transforme a situação dos sujeitos oprimidos por esse sistema. (PEREIRA, 2011, p. 52)

Importa pensar uma educaçáo que promova conhecimentos capazes de impulsionar atitudes voltadas à mudança, que qualifique o sujeito autônomo. No ambiente de prisão, é preciso pensar em mudança. A dinâmica 
educativa fundamenta açóes que podem reorganizar os espaços, articular profissionais e promover transformaçóes. Para conduzir a proposta de educação social, os profissionais envolvidos na dinâmica prisional, educadores em especial, precisam assumir uma postura de agentes de mudança que reconheçam, nas pessoas privadas de liberdade, educandos com direito à participação social. A educação social auxiliará, nesse sentido,

Como referente aglutinador de miradas políticas, pedagógicas, éticas e institucionales que puedem posibilitarla implementación de las responsabilidades cívicas y el reconocimiento de los derechos culturales para todas las identidades, tambien para las personas presas. (SOLBES; MERINO, 2016, p. 24)

O compromisso com o trabalho educativo social nas prisóes deve estar fundamentado em reflexóes que levem a açóes mais significativas e que acreditem realmente na mudança, na transformação, na direção de uma concepção verdadeira de liberdade, própria de uma sociedade de sujeitos emancipados. A concepção de liberdade, nessa direção,

[...] não se refere à situação da liberdade de ir e vir fisicamente e livre do cárcere, mas liberdade no sentido de consciência dos direitos dos internos a participarem da efetivação de uma educação que se preocupe com a humanização dos sujeitos, mesmo que tenham praticado crimes. (RIBEIRO; MACHADO, 2016, p. 76)

A prática se dará a partir da discussão, pela coletividade, das ações a desenvolver na instituição penal e pela união de forças dos diferentes segmentos implicados na definição de um propósito educacional unificado. A educação, portanto, é um pilar importante na redução dos danos prisionais e pode significar, se repensada pela educaçáo social, um eixo significativo na transformação do sujeito, exercendo sua função de mudança da realidade dessas pessoas e contribuindo na luta por dignidade.

O significado da educação social parte do conceito de enfrentamento ou embate dos problemas existentes e do atendimento das necessidades diárias, observando que toda reflexão e ação é educativa e, por conseguinte, transformadora. Essa educação, que acontece em todo o ambiente, per- 
mite que a pessoa privada de liberdade interprete sua realidade, desenvolva a compreensão do coletivo e entenda o papel relevante das suas açóes no contexto em que está inserido. Auxilia-o na elaboração de estratégias para enfrentar as tensões geradas no plano intramuros e para elaboração de projetos de vida extramuros. $\mathrm{Na}$ educação social, a função da educaçáo prisional se modifica e encontra uma

[...] função promotora e dinamizadora de uma sociedade que educa e de uma educaçáo que socialize e (re) integre, ao mesmo tempo que ajuda o educando a evitar situaçôes de risco, a sustentar um equilíbrio e a reparar a dificuldade e/ou conflito social. (MARTINS, 2013, p. 10)

Nesse sentido, a função da escola é incluir seus conteúdos e domínios científicos a efeitos de socialização, legitimando a função transformadora da educação na sociedade. Assim, a prática educativa contribui para a construção do sujeito emancipado e amplia o vir a ser da pessoa privada de liberdade, numa tentativa de superar as condiçóes estruturais existentes.

\section{Consideraçóes finais}

A análise detectou a inter-relação de forças configuradas na tutela prisional e nos responsáveis pelo atendimento da pessoa privada de liberdade. Nesses espaços, fundamentados nos discursos jurídicos, encontram-se teias sócio-políticas que desdobram em conflitos, muitas vezes ocultados pela submissão das instituiçôes escolares à gestão prisional. As relações de coexistência institucional mostraram espaço de domínio, ficando explícita a relação de poder estabelecido. A relação de forças que se apresentou no enfrentamento tem impacto direto na garantia de direitos à educaçáo da pessoa presa.

Nas visitas realizadas, a leitura do espaço prisional escolar evidenciou a educação como uma atividade determinada pela utilização territorial. A configuração do espaço escolar fica submetida à disciplina própria do caráter prisional da instituiçáo; o crescimento carcerário conduz a novos conflitos, tornando o ambiente cada vez mais precário, surtindo efeitos que, consequentemente, impedem o atendimento educacional com qualidade para todos. 
As propostas pedagógicas das escolas implantadas nas penitenciárias paranaenses não apresentaram possibilidades de superação dessas condiçôes estruturais. Porém, a verificação dos espaços físicos cedidos às escolas implantadas sinaliza que, se ocorresse esta preocupação, a estrutura física significaria uma das garantias da qualidade e permanência das açóes educativas dentro de cada instituição prisional. Assim, a impraticabilidade da educação pela estrutura é uma circunstância que precisa ser modificada pelas políticas prisionais.

Nesse sentido, problematiza-se a intencionalidade de ressocialização e seu fundo jurídico penal em detrimento do humanizador. Propóe-se, à vista disso, um processo educativo emancipador que supere a condiçáo da própria pena e da conjuntura que pode ter levado à situação de violência. Tal propósito se aproxima da práxis exercida pela Educação Social e proposta no campo acadêmico pela Pedagogia Social. Esta, por sua vez, representa o campo em que seria possível habilitar todos os segmentos do contexto prisional como educativos, integrando-os numa ação que, articulada, poderia alcançar a transformação do sujeito preso em prol de condiçóes mais dignas dentro e fora da prisão.

A Pedagogia Social pode contribuir na elaboração de um Projeto Político-Pedagógico comum às instituições, além de modificar a dinâmica prisional, transformando as práticas institucionais desiguais em ações coletivas. Pode, ainda, articular os profissionais prisionais e educacionais numa ação que melhoraria a convivência prisional e instigaria a elaboração de projetos de vida extramuros apoiados em experiências vividas dentro de um ambiente transformador que a prisão deveria assumir. Dessa maneira, a participação social modificará atitudes e contribuirá para o enfrentamento de problemas que possam surgir no ambiente de encarceramento e nos embates que surgirão fora desse espaço.

\section{Referências}

BARATTA, Alessandro. Criminologia crítica e crítica do Direito Penal: introdução à sociologia do direito penal. Trad. Juarez Cirino dos Santos. 3. ed. Rio de Janeiro: Revan: Instituto Carioca de Criminologia, 2002. 
BLAZICH, Gladys Susana. La educación em contextos de encierro. Revista Iberoamericana de Educación. n. 44, 2007. p. 53-60.

BRASIL. Resolução no 2, de 19 de maio de 2010. Dispóe sobre as Diretrizes Nacionais para a oferta de educação para jovens e adultos em situação de privação de liberdade nos estabelecimentos penais. Lex: Diário Oficial da União, seção 1, p. 1, maio, 2 trim, 2010. Disponível em: <http://portal.mec.gov.br/index.php?option=com_ docman\&view=download\&alias=5142-rceb002-10\&Itemid=30192> Acesso em 15 jan. 2017.

BRASIL. Ministério da Justiça e Segurança Pública. Departamento Penitenciário Nacional - Levantamento Nacional de Informaçóes Penitenciária (INFOPEN) - Junho 2016. Brasília: Ministérios da Justiça e Segurança Pública. Departamento Penitenciário Nacional, 2017.

BRASIL. Resolução n 06, de 07 de dezembro de 2017. Dispóe sobre a flexibilização das Diretrizes Básicas para Arquitetura Penal do Anexo 1 da Resolução no 9 de 18 de novembro de 2011 que trata das Diretrizes da Arquitetura Penal. Lex: Diário Oficial da União, seção 1, p. 74, dez. 4. trim. 2011. Disponível em <www.dpu.def.br/images/ stories/Infoleg/2017/12/13/cnpcp.pdf> Acesso em 30 mar. 2018.

CALIMAN, Geraldo. Pedagogia Social: contribuiçôes para a evolução de um conceito. In: SILVA, Roberto. (org.) Pedagogia Social: contribuiçóes para uma teoria geral da educação social. v. 2, São Paulo: Expressão e Arte, 2011.

CORDEIRO, Suzann. Até quando faremos relicários? A função social do Espaço Penitenciário. 2. ed. rev. e ampl. Maceió: Edufal, 2010.

GADOTTI, Moacir. Educação Popular, Educação Social, Educação Comunitária: conceitos e práticas diversas, cimentadas por uma causa comum. Revista Diálogos. IV Congresso Internacional de Pedagogia Social: domínio epistemológico. V. 18, n. 1, dez. 55-65, 2012.

GRACIANI, Maria Stela Santos. Desafios metodológicos da prática social transformadora ou teorizar a prática social para transformá-la. In: SILVA, Roberto da. (org.) Pedagogia Social: contribuições para uma teoria geral da educação social. v. 2, São Paulo: Expressão e Arte, 2011.

IPARDES. Instituto Paranaense de Desenvolvimento Econômico e Social. Instituto Brasileiro de Geografia e Estatística (IBGE). Pesquisa Nacional por Amostra de Domicílios Continua (PNAD Continua). Curitiba, 2016.

IPEA. Instituto de Pesquisa Econômica Aplicada. Reincidência Criminal no Brasil: relatório de pesquisa. Rio de Janeiro: IPEA, 2015. 
LOURENÇO, Arlindo da Silva. Os processos educativos nas prisóes: suas regularidades e suas singularidades. In: LOURENÇO, Arlindo da Silva; ONOFRE, Elenice Maria Cammarosano. (orgs). O espaço da prisão e suas práticas educativas: enfoques e perspectivas contemporâneas. São Carlos: EdUFSCar, 2011.

MARTINS, Ernesto Candeias. A Pedagogia social/Educação social nos meandros da comunidade e da escola. Educareducare. ano XV, n. 1, II série, 2013. Disponível em < https://repositorio.ipcb.pt/handle/10400.11/2654> Acesso em 20 jun 2018.

MONTEIRO, Felipe Mattos. CARDOSO, Gabriela Ribeiro. A seletividade do sistema prisional brasileiro e o perfil da população carcerária; um debate oportuno. Civitas. v. 13. n. 1. Porto Alegre, jan. abr, 2013, p. 93-117.

ONOFRE, Elenice Maria Cammarosano. Escola da prisão: espaço de construção da identidade do homem aprisionado? In: ONOFRE, Elenice Maria Cammarosano. Educação escolar entre as grades. São Carlos: EdUFScar, 2007.

PEREIRA, Antonio. A educação-pedagogia no cárcere, no contexto da pedagogia social: definiçóes conceituais e epistemológicos. Revista Educação Popular. Uberlândia, v.10, p. 38-55, jan/dez, 2011.

RESENDE, Selmo Haroldo de. A vida na prisão: histórias de objetivação e sujeição na educação do condenado. In: LOURENÇO, Arlindo da Silva; ONOFRE, Elenice Maria Cammarosano (org.). O espaço da prisão e suas práticas educativas: enfoques e perspectivas contemporâneas. São Carlos: EdUFSCar, 2011.

RIBEIRO, Bruna Carolina de Alfaia; MACHADO, Edina Fialho. Pedagogia Social no Cárcere em busca de humanização. Revista Diálogos: extensão, metodologias e inclusão. Brasília, v. 20, n. 01, nov, 2016. Disponível em <https://portalrevistas.ucb.br/index. php/RDL/article/viewFile/6806/4799> Acesso em 20 jun. 2018.

RODRIGUES, Vanessa Elisabete Raue. Lembranças no cárcere: a evasão na idade própria do aluno preso e suas possibilidades na educação prisional. In: CONGRESSO NACIONAL DE EDUCAÇÃO. Curitiba. Anais eletrônicos... Curitiba, 23 a 26 de setembro de 2013/Pontifícia Universidade Católica do Paraná. Curitiba: PUCPR, 2013. Disponível em < http://educere.bruc.com.br/arquivo/pdf2013/15124_7080.pdf> Acesso em 10 nov. 2013.

RODRIGUES, Vanessa Elisabete Raue. A relação da Educação e do Trabalho na Penitenciária Industrial de Guarapuava: mudanças e permanências históricas. 2015. 130 p. Dissertação (Mestrado em Educação) - Universidade Estadual do Centro-Oeste, Guarapuava.

RODRIGUES, Vanessa Elisabete Raue; QUADROS, Sheila Fabiana de; OLIVEIRA, Rita de Cássia da Silva. A dialética marxista nas implicações educacionais do sistema prisional. In: PEREIRA, Ana Lúcia; BRANDT, Célia Finck; GABRIEL, Fábio Antônio. Fundamentos Epistemológicos da Educação. Rio de Janeiro: Multifoco, 2017. 
SANTOS, Silvio dos. A educação escolar na prisão sob a ótica de detentos. In: ONOFRE, Maria Cammarosano (org). Educação escolar entre as grades. São Carlos: EdUFScar, 2007.

SAPORI, Luis Flávio. SANTOS, Roberta Fernandes. MAAS, Lucas Wan Der. Fatores Sociais determinantes da reincidência criminal no Brasil. Revista Brasileira de Ciências Sociais. vol. 32, n. 94, junho/2017. Disponível em <http://www.scielo.br/pdf/rbcsoc/ v32n94/0102-6909-rbcsoc-3294092017.pdf> Acesso em 20 maio 2017.

SCARFÓ, Francisco; BREGLIA, Florencia; FREJTMAN, Valéria. Sociedade Civil e Educação Pública nos presídios: questóes para reflexão. In: LOURENÇO, Arlindo da Silva; ONOFRE, Elenice Maria Cammarosano. (orgs). O espaço da prisão e suas práticas educativas: enfoques e perspectivas contemporâneas. São Carlos: EdUFSCar, 2011.

SILVA, Haroldo Caetano da. Ensaio sobre a pena de prisão. Curitiba: Juruá, 2009.

SILVA, Roberto da. Visóes e concepçóes necessárias a uma teoria geral da educação social. In: (org.) Pedagogia Social: contribuições para uma teoria geral da educação social. v.2, São Paulo: Expressão e Arte, 2011.

SILVA, Roberto da; MOREIRA, Fábio; OLIVEIRA, Carolina Bessa Ferreira de. Ciências, Trabalho e Educação no sistema penitenciário brasileiro. Caderno Cedes. Campinas, v.36, n.98, p.9-24, jan-abr, 2016.

SILVA, Roberto da (org). Didática no Cárcere II: entender a natureza para entender o ser humano e seu mundo. São Paulo: Giostri Editora, 2018.

SOLBES, Victor S. Martin; MERINO, Eduardo S. Vila. Si nada Cambia, Todo continua igual: la educación social y sus ausências em el âmbito penitenciario. RES Revista de Educación Social. n. 22. Enero, 2016. Disponível em < www.eduso.net/res/ admin/archivo/docdow.php?id=734> Acesso em 20 jun. 2018.

WAISELFISZ, Julio Jacobo. Mapa da Violência- 2014. Rio de Janeiro: Fracso, 2014.

Recebido em 7 fev. 2019 / Aprovado em 19 mar. 2019

\section{Para referenciar este texto:}

RODRIGUES, V. E. R.; OLIVEIRA, R. C. S. A pedagogia social nas implicações prisionais e práticas escolares intramuros: reflexóes de um estudo no estado do Paraná. EccoS - Revista Científica, São Paulo, n. 48, p. 7 I-94. jan./mar. 2019.

Disponível em: <https://doi.org/I0.5585/EccoS.n48.II549>. 